\title{
Effect of Sitagliptin in Combination with Glimepiride on Glycemic Control and Islet Cell Diameter/Proliferation in A Model of Type 2 Diabetic Rats
}

\author{
Noha A. Mohamed ${ }^{1}$, Sawsan A. Zaitone ${ }^{2}$, Yasser M. Moustafa ${ }^{2}$ \\ ${ }^{1}$ (Forensic Medicine Authority, Ministry of Justice, Ismailia, Egypt) \\ ${ }^{2}$ (Department of Pharmacology \& Toxicology, Faculty of Pharmacy, Suez Canal University, Ismailia 41522, \\ Egypt)
}

\begin{abstract}
The aim of the present study was to investigate the effect of monotherapy with sitagliptin, or its combination with glimepiride in glycemic control, islet cell diameter and its proliferation in type 2 diabetic rats. Rats were fed with a high fat diet followed by injection with a low dose of streptozotocin to induce type 2 diabetes. Then, rats were switched to normal diet and for other 28 days. Monotherapy with sitagliptin did not affect the body weight, while its combination with glimepiride did not induce a significant change. The combination increased the \% change in body weight compared to sitagliptin alone. All the treatment regiment enhanced glucose clearance as indicated by a reduction in the area under the curve. Pancreatic immunohistochemistry and morphometric analysis were performed to measure the diameter of islet cells, insulin-positive area and the number of Ki-67 positive nuclei. In sitagliptin group, diameter of large-sized islets was 2-fold greater than those observed in diabetic group. The monotherapy with glimepiride did not change the islet-cell diameter. Further, the combination group showed better glycemic control and greater cell proliferation compared to monotherapies. Consequently, we conclude that the combination therapy of sitagliptin/glimepiride has synergistic effect.
\end{abstract}

KEY WORDS: beta cell, diabetes, glimepiride, sitagliptin, rats.

\section{INTRODUCTION}

In the natural history of type 2 diabetes, the development of insulin resistance, impaired glucose tolerance and finally type 2 diabetes occurs gradually over many years. As the disease develops, however, there is a progressive loss of beta-cell function. As type 2 diabetes is a progressive disease, intensification of therapy is normally required over time. Current therapies may also be associated with an increased risk of hypoglycaemia (sulphonylureas and insulin), weight gain (sulphonylureas, thiazolidinediones and insulin), and gastrointestinal intolerance (metformin), which represent major barriers to optimal glycemic control [1].Treatment with a single antihyperglycemic agent is often unsuccessful in achieving and/or maintaining glycemic control in patients with type 2diabetes, and many patients require combinations of antihyperglycemic agents [2].Beside the gene background, unhealthy life style such as high-energy intake is correlated with type 2 diabetes. Thus, scientists try to obtain a type 2 diabetes animal model following the real course. The general strategy is using high-energy diet feeding for a period with the purpose to induce mild insulin resistance at first, and then an injection of a low dose of STZ to make partial dysfunction of beta cell for suppressing the insulin secretion, which works as a compensation to insulin resistance with the result of persistent hyperglycemia. Recently, there is a considerable interest in the therapy of type 2 diabetes, with a focus on the development and use of new agents that exhibit improved efficacy and safety relative to current available medicines. Incretion hormones such as glucagon-like peptide-1 (GLP-1) and glucose-dependent insulinotropic polypeptide (GIP) can act as growth and differentiating factors for pancreatic beta cells [3]. Promising pharmacological approaches recently approved for the treatment of type 2 diabetes include two incretin-based therapies, the glucagon-like peptide-1 receptor (GLP-1R) agonists or molecules that inhibition the breakdown of incretin hormones (i.e. DPP-4 inhibitors)[4].

The new treatment strategy is the use of GLP-1 or other incretin mimetic. This has been shown to increase beta cell mass by decreasing apoptosis and increasing cell replication or neogenesis [5].Using GLP-1 as a therapeutic agent has some drawbacks due to its short half-life as a result of inactivation by the enzyme DPP-4 [6]. Therefore, the use of DPP-4 inhibitors which enhance the circulating levels of endogenous GLP-1 and improve glycemia are more preferred. Gliptins are a novel class of oral anti-diabetic agent that enhance and prolong the physiological actions of incretin hormones by competitively antagonizing the enzyme DPP-IV. Animal studies demonstrate the anti-diabetic properties of DPP-IV inhibitors, with a delay of progression from 
impaired glucose tolerance to type 2 diabetes [7], an improvement in glucose tolerance and insulin secretion $[8,9]$ as well as an improvement in beta-cell function and an increase in hepatic and peripheral insulin sensitivity [10]. One of the most recent DPP-4 inhibitor drugs is sitagliptin [11].Sitagliptin, an organic molecule, appears to be selective for DPP-4 enzyme [12]. Sitagliptin is rapidly absorbed; achieving peak plasma levels $1-6 \mathrm{~h}$ after dosing. Its half-life is $8-14 \mathrm{~h}$ with bioavailability of $87 \%$, with or without food [13, 14]. About $80 \%$ of the dose is excreted unchanged by the kidney, with $15 \%$ of the bioavailability drug metabolized by CYP3A4 and CYP2C8 in the liver $[13,15]$.Glimepiride stimulates the pancreas to release more insulin, both right after a meal and then over several hours so it taken with meals, on the other hand it have some adverse effects(hypoglycemia, occasional skin rash, irritability, upset stomach).The synergistic action of using combination of sitagliptin and traditional antidiabetic agent regards to the action of sitagliptin which increase of the beta cell mass through its replication which lead to increase the effect of this traditional agents (glimepiride). The objective of the current study was to evaluate the effect of the DPP-4 inhibitor, sitagliptin, in combination with glimepiride in modifying the progression of islet dysfunction and loss of islet cell replication/proliferation in a rodent model of type 2 diabetes induced by feeding of HFD followed by injection of a low dose of STZ.

\subsection{Drugs and chemicals}

\section{MATERIALS AND METHODS}

Streptozotocin (STZ) was purchased from Sigma-Aldrich (MO, USA). Sitagliptin (Januvia ${ }^{\circledR}$ tablet) was obtained from Merck Sharp \& Dohme Ltd (Pavia, Italy).Glimepiride was a gift from Medical Union Pharmaceuticals (Abu-Sultan, Ismailia, Egypt). All other chemicals and solvents were of highest analytical grade. The feed ingredients such as lard and sucrose were procured from the commercial sources. Citric acid, sodium citrate and sodium carboxymethyl cellulose (Na-CMC) were also obtained from ADWIC CO. (Cairo, Egypt).

\subsection{Experimental animal and diet}

Male Wistar rats weighing 220-270 g were obtained from the National Center of Research (Cairo, Egypt). Rats were housed in stainless steel cages in a normal light-dark cycle at around $22{ }^{\circ} \mathrm{C}$. Rats were fed with a high-fat diet (HFD) for four weeks, which was prepared by mixing $20 \%$ sucrose (w/w) and $10 \%$ lard (w/w) into basal diet and water ad libitum. Normal control rats were fed with basal diet. Food was replaced daily and any uneaten portions were discarded. Body weights of rats were recorded weekly. All experiment protocols followed the guidelines of the Institutional Animal Care and Use Committee at the Faculty of Pharmacy, Suez Canal University, Ismailia, Egypt.

\subsection{Induction of diabetes}

Rats were fed with HFD for four weeks. Fasting blood glucose level was recorded every three days. After these four weeks, the rats were fasted overnight then received single intraperitoneal injection of freshly prepared STZ $(30 \mathrm{mg} / \mathrm{kg})$ in citrate buffer $(0.1 \mathrm{M}, \mathrm{pH}=4.5)$ in a volume of $2 \mathrm{ml} / \mathrm{kg}$. Three days after STZ administration, fasting blood glucose level of each rat was recorded. Rats with fasting blood glucose level more than $135 \mathrm{mg} / \mathrm{dl}$ were considered diabetic and included in the experiment. The control rats were fed with a basal diet and received the vehicle (citrate buffer) parallel to STZ. Treatment with drugs and there combinations started on the third day after STZ injection (i.e. after the estimation of blood glucose).

\subsection{Experimental design}

Forty rats were used in the present study and divided into five groups, eight rats each. Group 1: Normal control rats, received citrate buffer $(\mathrm{pH}=4.5,1 \mathrm{ml} / \mathrm{kg})$, Group 2-7: rats were fed with the HFD for four weeks followed by a single injection of streptozotocin $(30 \mathrm{mg} / \mathrm{kg}$, i.p.). Group 2: rats received Na-CMC solution (2 $\mathrm{ml} / \mathrm{kg}$, p.o.). Group 3: rats were treated with sitagliptin $(10 \mathrm{mg} / \mathrm{kg} / \mathrm{day}$, p.o.). Group 4: rats were treated with glimepiride $(0.5 \mathrm{mg} / \mathrm{kg} /$ day, p.o.); Group 5: rats were treated with a combination of both drugs in the same aforementioned doses. In general, drugs were administered orally as a suspension in $1 \%$ sodium carboxymethyl cellulose (Na-CMC) solution and continued for a period of 28 days.

\subsection{Oral glucose tolerance test}

At the end of experiment, animals were fasted overnight andadministered5 $\mathrm{ml}$ of glucose solution $(2 \mathrm{~g} / \mathrm{kg}$ body weight) orally. Glucose disposal was analyzed by measuring random blood glucose rat at different time point $0,30,60,90$ and $120 \mathrm{~min}$. Blood samples were obtained by tail prick and glucose was measured by Accu-check go blood glucose meter (Roche Diagnostic ${ }^{\circledR}$, Germany).The body weights of all the experimental rats were monitored every week. 


\subsection{Biochemical assays}

Blood samples were collected through the orbital sinus, under light ether anesthesia; centrifuged at $1000 \times \mathrm{g}$ for $15 \mathrm{~min}$, serum samples were separated and stored at $-20^{\circ} \mathrm{C}$ for the estimation of various biochemical parameters. After that, rats were sacrificed by cervical decapitation. The pancreas was rapidly dissected and stored in $4 \%$ phosphate-buffered formalin for histological examination.

\subsection{Histopathology and immunohistochemistry}

After excision, the whole pancreas from each rat was immediately weighed and kept in $4 \%$ phosphatebuffered formalin, fixed and subsequently sectioned (5- $\mu \mathrm{m}$ thick) throughout its length and 5 sections were taken at regular intervals for insulin immunostaining. Paraffin-embedded pancreatic sections were stained first for hematoxylin/eosin so as to record the diameter of islet cells. Then other two sections were immunostained for insulin and Ki-67 (a marker for cell proliferation).Immunohistochemistry for insulin staining in pancreatic tissues were performed using primary antibody (mouse anti-insulin, NeoMarkers, CA, USA) followed by a reaction with secondary antibody (goat polyclonal secondary antibodies against mouse IgG, Abcam ${ }^{\circledR}$, Cambridge, UK).Immunohistochemistry for ki-67was performed using rabbit polyclonal primary antibodies against Ki-67(1:50;Abcam, Cambridge, UK) followed by a reaction with secondary antibody (biotinylated goat anti-rabbit antibodies, Abcam ${ }^{\circledR}$, Cambridge, UK).After conjugation with streptavidin-biotin-peroxidase complex(Broad spectrum LAB-SA detection system, Invitrogen),3,3-diaminobenzidine (DAB, Sigma-Aldrich ${ }^{\circledR}$, MO, USA) was used as a chromogen, and Mayer's hematoxylin was used as a counterstain.

\subsection{Pancreatic immunohistochemistry-morphometric analysis}

All analyses were performed in a blinded fashion where the investigator was not aware of the treatment groups. The morphometric analysis were done manually by a stereological method with mathematical support using an image analysis system "Image J $1.45 \mathrm{~F}$ " (National Institute of Health, USA) to measure the diameter of the islet, the optical density of insulin-positive area and the number of ki-67 positive nuclei at 400x magnification. These cells which present in the endocrine and the exocrine pancreatic parenchyma, therefore, number of immunpositive nuclei were measured after identification of endocrine pancreatic beta cell from the insulin immunslides.

\subsection{Statistical analysis}

All data were collected, tabulated and expressed as mean \pm SEM. Quantitative parametric variables were analyzed using one-way analysis of variance (ANOVA) followed by Bonferroni's post-hoc test. The Statistical Package of Social Science (SPSS) program version 17, (Chicago, IL, USA) was used for the statistical analysis. A $P$ value $<0.05$ was considered to be statistically significant.

\section{RESULT}

\subsection{Percentage mortality and percentage change in body weight}

At the end of the study, the normal and diabetic groups showed $0 \%$ mortality whereas; monotherapies with either sitagliptin or glimepiride produced $12.5 \%$ mortality. The combination group showed significantly higher mortality (37.5\%) compared to diabetic rats. Diabetic rats showed a lower \% change in body weight compared to normal rats $(3.54 \pm 1.25$ vs. $25.72 \pm 2.15, P \leq 0.05$, Table 1$)$. Monotherapy with sitagliptin significantly reduced the $\%$ change in body weight compared to the diabetic rats. However; monotherapy with glimepiride did not induce a significant change in percent change in body weight. The combination of both drugs produced greater \% change in body weight compared to monotherapy with sitagliptin (Table 1). 
Table 1: Effect of sitagliptin $(10 \mathrm{mg} / \mathrm{kg} /$ day $/ 28$ day $)$, glimepiride $(0.5 \mathrm{mg} / \mathrm{kg} /$ day $/ 28$ day $)$ and their combination (with same dose) on percent change in body weight and percent mortality . BWt : body weight.

Values are expressed as mean \pm S.E.M. and analyzed using one-way ANOVA followed by Bonferroni's multiple comparisons test. ${ }^{*}$ Compared to normal group at $P<0.05$. ${ }^{\dagger}$ Compared to diabetic group at $P<0.05$.

${ }^{*}$ Compared to sitagliptin group at $P<0.05$. ${ }^{\$}$ Compared to glimepiride group at $P<0.05, n=4-8$.

\begin{tabular}{|c|c|c|c|c|}
\hline Group & $\begin{array}{c}\% \\
\text { mortality }\end{array}$ & $\begin{array}{l}\text { Baseline } \\
B W t(g)\end{array}$ & $\begin{array}{c}\text { Final } \\
B W t(g)\end{array}$ & $\begin{array}{l}\text { \% change } \\
\text { in } B W t\end{array}$ \\
\hline Normal & 0 & $232.2 \pm 15.7$ & $\begin{array}{l}291.8 \pm \\
20.02\end{array}$ & $\begin{array}{r}25.72 \pm \\
2.15\end{array}$ \\
\hline Diabetic & 0 & $240 \pm 6.3$ & $264 \pm 6.5$ & $\begin{array}{l}3.54 \pm \\
1.25^{*}\end{array}$ \\
\hline $\begin{array}{r}\text { Sitaglipti } \\
n\end{array}$ & $12.5^{\dagger}$ & $226.2 \pm 9.4$ & $205 \pm 18.3$ & $\begin{array}{l}-9.97 \pm \\
3.53^{\dagger}\end{array}$ \\
\hline $\begin{array}{r}\text { Glimepiri } \\
\text { de }\end{array}$ & $12.5^{\dagger}$ & $234.2 \pm 9.7$ & $249.8 \pm 16$ & $\begin{array}{c}6.55 \pm \\
2.68\end{array}$ \\
\hline $\begin{array}{l}\text { Sitaglipti } \\
n+\text { glimepiride }\end{array}$ & $37.5^{\dagger}$ & $242.2 \pm 17$ & $\begin{array}{r}264.5 \pm \\
12.6\end{array}$ & $\begin{array}{l}8.20 \\
\pm 8.14\end{array}$ \\
\hline
\end{tabular}

\subsection{Oral glucose tolerance test}

In the present study, diabetic rats showed greater area under the curve (AUC) compared to normal rats. Treatment with sitagliptin $(10 \mathrm{mg} / \mathrm{kg})$, glimepiride $(0.5 \mathrm{mg} / \mathrm{kg})$ or their combination reduced the AUC compared to the diabetic rats (Fig $1 \mathrm{~A} \& \mathrm{~B}$ ). The AUC in the combination group was smaller than that calculated in sitagliptin group.
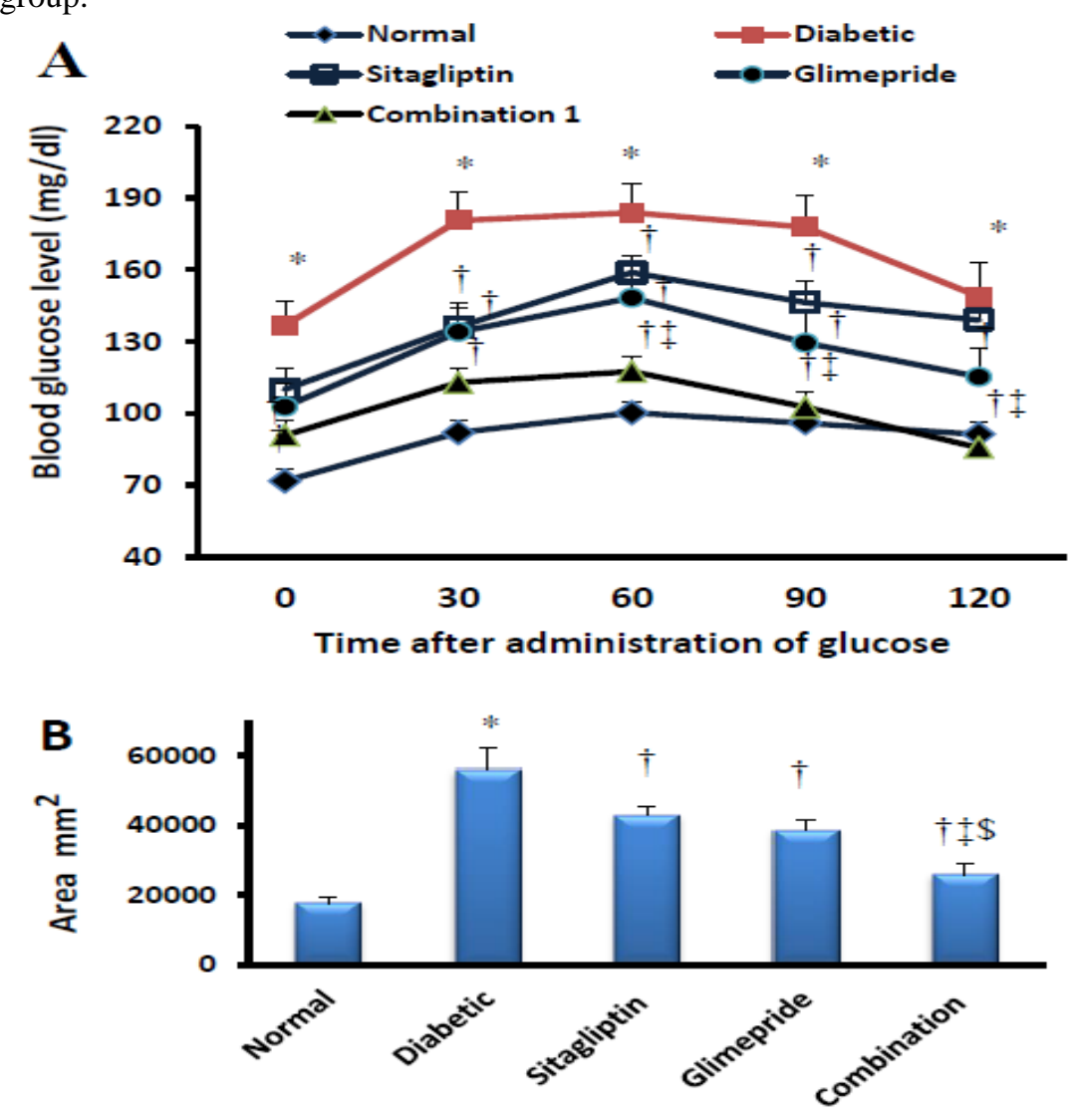
Figure 1: Oral glucose tolerance test in the experimental groups. A) Effect of the combination of sitagliptin and glimepiride on blood glucose level compared to their monotherapies. B) Area under the curve estimated from the oral glucose tolerance test. Data are presented as mean \pm SEM and analyzed using one-way ANOVA followed by Bonferroni's multiple comparisons test. *Compared to normal group at $P \dagger$ Compared to diabetic group at $P \ddagger$ Compared to sitagliptin group at $P$ \$Compared to glimepride group at $P<n=4-8$.

\subsection{Biochemical assays}

Liver enzyme activities (GOT and GPT) were higher in the diabetic group compared to the normal group. Glimepiride was the sole treatment that reduced serum GOT compared to diabetic group. On the other hand, all the treatment regimens reduced serum GPT compared to diabetic group. Analysis of serum lipids indicated that the diabetic group showed high serum total cholesterol, triglyceride and LDL but lower HDL in comparison to the normal group. Monotherapy with sitagliptin, glimepiride or their combination reduced the serum triglyceride and LDL while increased HDL compared to the diabetic group (Table 2). Further, the combination of sitagliptin plus glimepiride improved these three parameters compared to monotherapy with sitagliptin.

Table 2: Effect of sitagliptin (10mg/kg/day/28day), glimepiride (0.5mg/kg/day/28day) and their combination (with same dose) on liver enzymes and lipid profile. G: groups, N: normal, D: diabetic, S: sitagliptin, G: glimepiride, GOT: Glutamic- Oxaloacetic Transaminase GPT: Glutamic - Pyruvic Transaminase, TG: triglyceride, LDL: low density lipoprotein, HDL: high density lipoprotein. Values are expressed as mean \pm S.E.M. and analyzed using one-way ANOVA followed by Bonferroni's multiple comparisons test. "Compared to normal group at $P<0.05$. ${ }^{\dagger}$ Compared to diabetic group at $P<0.05$. ${ }^{*}$ Compared to sitagliptin group at $P<0.05$. ${ }^{\$}$ Compared to glimepiride group at $P<0.05, n=4-8$.

\begin{tabular}{|c|c|c|c|c|c|c|}
\hline $\mathrm{G}$ & $\begin{array}{c}\text { GOT } \\
\text { (unit/ml) }\end{array}$ & $\begin{array}{c}\text { GPT } \\
\text { (unit/ml) }\end{array}$ & $\begin{array}{l}\text { Cholesterol } \\
(\mathrm{mg} / \mathrm{dl})\end{array}$ & $\begin{array}{c}\mathrm{TG} \\
(\mathrm{mg} / \mathrm{dl})\end{array}$ & $\begin{array}{l}\text { LDL } \\
(\mathrm{mg} / \mathrm{dl})\end{array}$ & $\begin{array}{c}\text { HDL } \\
(\mathrm{mg} / \mathrm{dl})\end{array}$ \\
\hline$N$ & $61.5 \pm 4.2$ & $41.8 \pm 3.849$ & $1.95 \pm 0.048$ & $27 \pm 0.9$ & $104.7 \pm 6.04$ & $84.88 \pm 3.6$ \\
\hline$D$ & $5.2^{91.1 \pm}$ & $102.5 \pm 9.9^{*}$ & $2.08 \pm 1.20 *$ & $40 \pm 2.3^{*}$ & $186.9 \pm 10.8^{*}$ & $52.36 \pm 4.8 *$ \\
\hline$S$ & $86.1 \pm 4.9$ & $67.3 \pm 5.94^{\dagger}$ & $2.22 \pm 1.27$ & $28 \pm 1.6^{\dagger}$ & $143.9 \pm 8.3^{\dagger}$ & $69.12 \pm 6.4^{\dagger}$ \\
\hline$G$ & $83.3 \pm 3.63^{\dagger}$ & $67.5 \pm 4.9^{\dagger}$ & $2.09 \pm 1.20$ & $29 \pm 1.7^{\dagger}$ & $154.3 \pm 8.9^{\dagger}$ & $62.88 \pm 1.7^{\dagger}$ \\
\hline $\begin{array}{l}S \\
+G\end{array}$ & $82.5 \pm 4.17$ & $i 8.25 \pm 6.67^{\dagger}$ & $2.23 \pm 1.28$ & $21 \pm 1.2^{\dagger \downarrow s}$ & $140.7 \pm 8.1^{\dagger \$}$ & $81.67 \pm 2.7^{\dagger \neq s \mathrm{~s}}$ \\
\hline
\end{tabular}

\subsection{Islet cell morphology}

Histopathological examination revealed that diabetic rats showed a reduction in the size of the islets and shrinking as well as spread of vacuoles (Fig. 2A). Monotherapy with sitagliptin produced a marked increase in the diameter of the islets of pancreatic beta cells compared to the diabetic group beside the absence of vacuoles and saving its shape uniform. The largest size islet in the diabetic group equaled 8,500 $\mu \mathrm{m}^{2}$ while the largest size islet in sitagliptin group equaled $13,480 \mu \mathrm{m}^{2}$. Monotherapy with glimepiride did not produce a change in the islet diameter compared to the diabetic group. In contrast, the combination of sitagliptin and glimepiride showed larger islet diameter compared to monotherapy with sitagliptin. The largest size islet in the combination group equaled $17,790 \mu \mathrm{m}^{2}$ (Fig $\left.2 \mathrm{~A} \& \mathrm{~B}\right)$. 

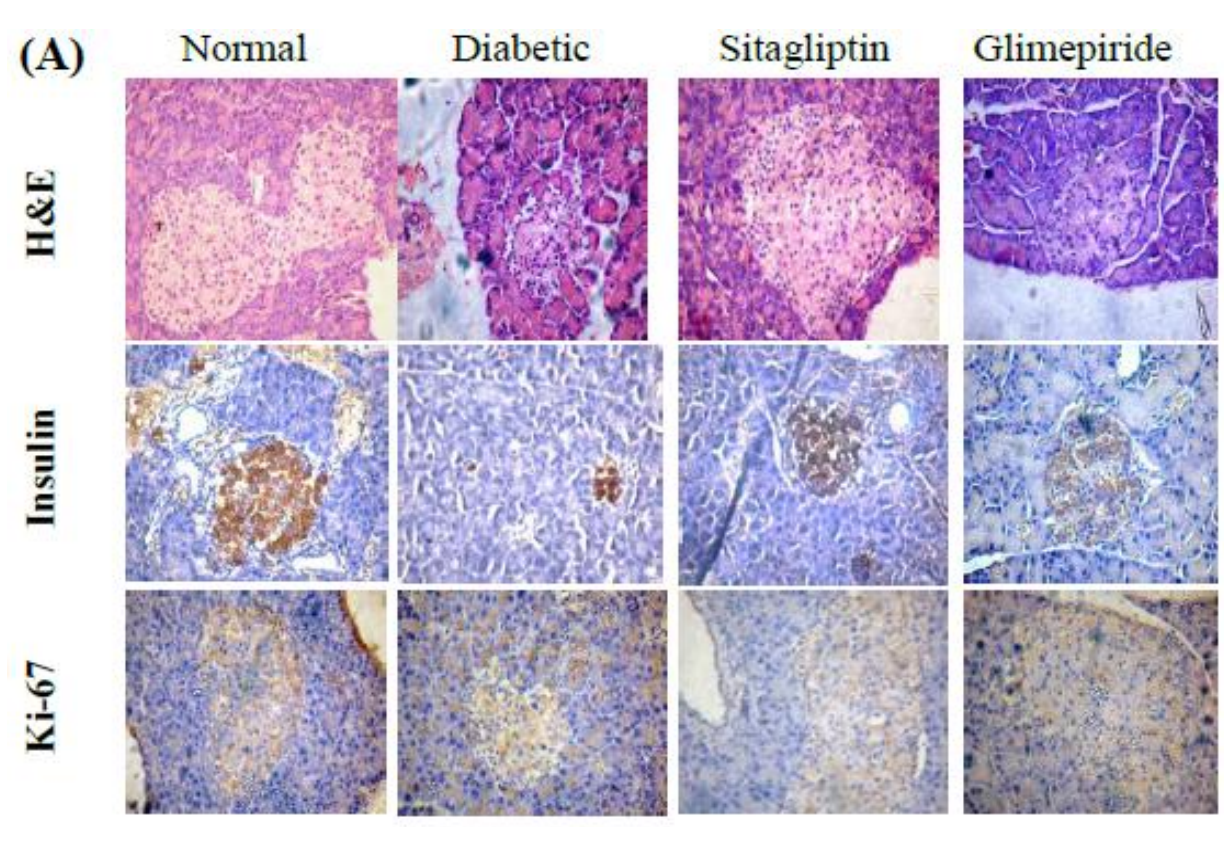

\section{Combination}

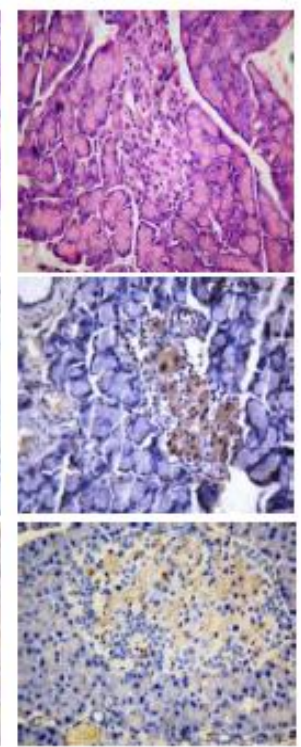

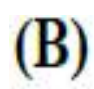

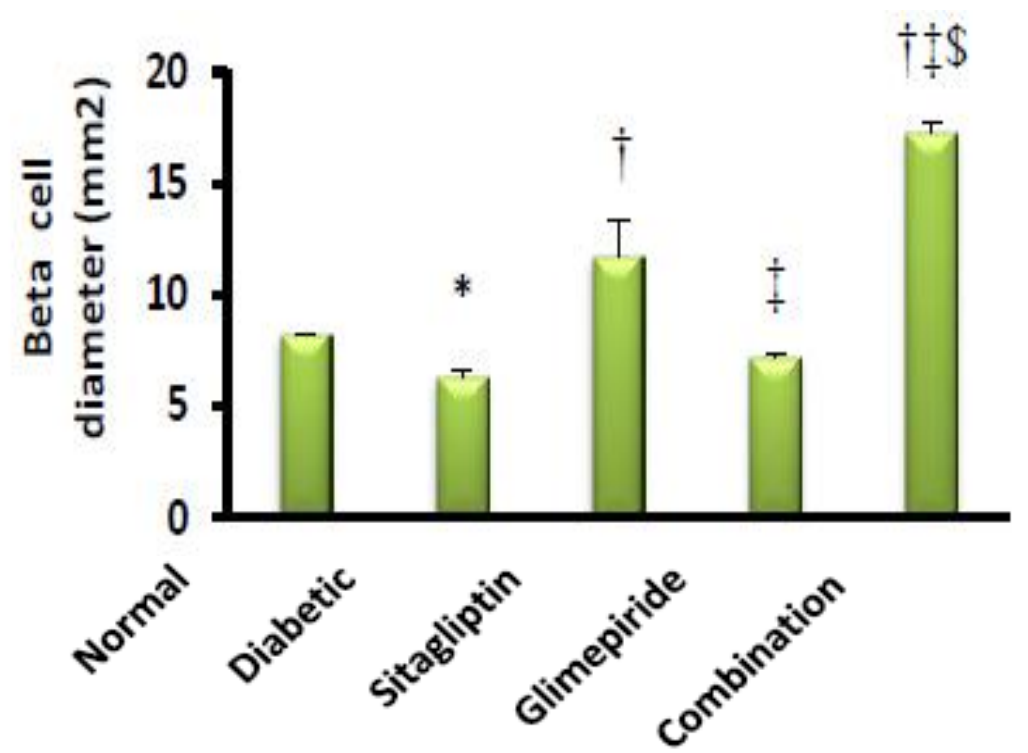

Figure 2: A) Histopathological pictures of the pancreatic islets of the experimental groups (hematoxylin \& eosin, immunostaining for insulin and $\mathrm{Ki}-$ at $40 \mathrm{x}$ magnification). The diameter (B), optical density of immunreaction. Data are presented as mean \pm SEM and analyzed using one-way ANOVA followed by Bonferroni's multiplecomparison test at $\mathrm{P}<0.05$. *Compared to normal group. †Compared to diabetic group. $\$$ Compared to sitagliptin group. \$Compared to glimepiride group, \#Compared to pioglitazone group, $n=4-8$.

\subsection{Immunohistochemistry for insulin and Ki-67}

Immunohistochemical staining for insulin showed lower optical density for immunpositive pancreatic islet cells in the diabetic rats compared to the normal rats. Treatment with sitagliptin, glimepiride or their combination increased the optical density for insulin immunostaining compared to the diabetic group $(P<0.05$, Fig 3A).Immunostaining for Ki-67 highlighted the presence of actively dividing cells in the normal group. The number of Ki-67 immunpositive nuclei was lower in diabetic rats compared to normal. Monotherapy with sitagliptin or all the sitagliptin combinations with glimepiride significantly increased the number of Ki-67 immunpositive nuclei compared to diabetic rats. However, monotherapy with glimepiride failed to produce a similar effect (Fig. 3B). 
(A)

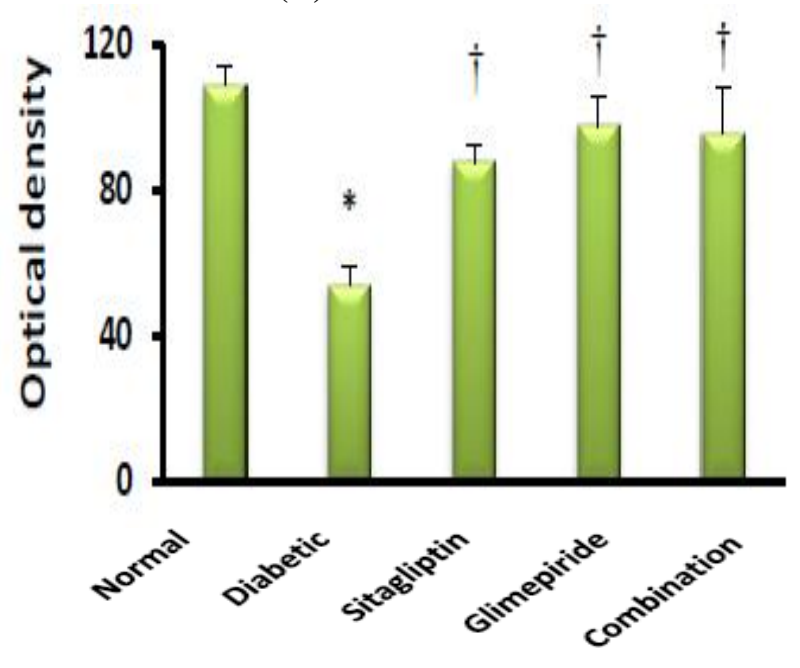

(B)

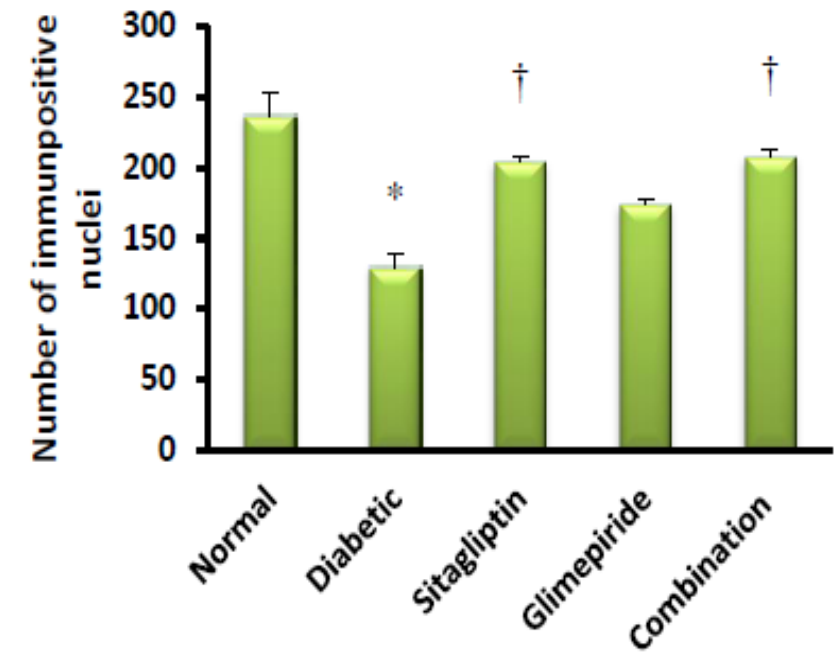

Figure 3: A) Histopathological pictures of the pancreatic islet of the experimental groups (hematoxylin \& eosin, immunostaining for insulin and $\mathrm{Ki}-$ at $\mathrm{x}$ magnification). Optical density of immunreaction and number of immunpositive nuclei (B) in the pancreatic islet cell. Data are presented as mean \pm SEM and analyzed using one-way ANOVA followed by Bonferroni's multiple-comparison test at $\mathrm{P}<0.05 .{ }^{*}$ Compared to normal group. $\dagger$ Compared to diabetic group. $\$$ Compared to sitagliptin group. \$Compared to glimepiride group, \#Compared to pioglitazone group, $\mathrm{n}=4-8$.

\section{DISCUSSION}

The current study was designed to explore the effect of sitagliptin alone and in combination with glimepiride on glycemic control and islet morphology in type 2 diabetic rats. Rats were fed with a HFD for four weeks followed with injection of with a low dose of STZ (30 mg/kg) to induce type 2 diabetes. Wang et al. [16] reported that the injection of a low dose of STZ $(30 \mathrm{mg} / \mathrm{kg})$ after a four-week feeding period of a HFD induced symptoms of human diabetes by markedly elevating serum glucose, total cholesterol and LDL levels. The new agents of DPP-4 inhibitors act through their effect on incretin hormones. Incretin hormones is represented mostly by two main types (GLP-1, GIP), which secreted from endocrine cells in the gastrointestinal tract, in response to ingestion of food. In the present study, monotherapy with sitagliptin decreased the percent change in body weight although its combination with glimepiride showed an increase. Differently, sitagliptin was found to be weight neutral, with weight changes similar to those for patients taking placebo. Karasik et al. [17] Further, Ahren et al. [18] reported anon significant decrease in body weight with the DPP-4 inhibitors in type 2 diabetic patients either as monotherapy or as combination therapy with metformin. These agents may also either induce weight loss (GLP-1R agonists) or are not associated with weight gain (DPP-4 inhibitors), in contrast to findings with other presently available treatments for type 2 diabetes [19]

In the current study, monotherapy with sitagliptin, glimepiride and their combination improved glucose tolerance as indicated by oral glucose tolerance test. It has been demonstrated that treatment with sitagliptin produced a low incidence of hypoglycemia $(0-4 \%)$ compared with glipizide $(17 \%)$ and placebo $(2.4 \%)$ in patients with type 2 diabetes. The Authors highlighted that sitagliptin, unlike glipizide, did not increase body weight compared to control patients Scott et al. [20]. Similarly, sitagliptin was compared to sulfonylurea (glimepiride) or thiazolidinediones (pioglitazone), it had the advantages of not producing weight gain or hypoglycemia. Mary et al. [21] concluded that sitagliptin could be an alternative therapy for adult patients who cannot tolerate other antidiabetic agents. Further, sitagliptin was reported to be well tolerated, causing no hypoglycaemia or weight gain in patient with type 2 diabetes with Roger et al. [22]. In current study, all the treatment regimens had favorable effects on serum lipid profile and liver enzymes; this agreed with the data obtained previously Pospisilik et al. [23]. The authors showed that long-term DPP-4 inhibition improved glucose tolerance, hyperinsulinemia, and beta-cell function in the VDF Zucker rat; these findings highlighted the potential utility of these compounds in diabetes therapy. Data from the same study indicated that OGTT and an in vitro determination of insulin-stimulated glucose uptake in isolated muscle provided an indirect evidence for a treatment-induced improvement in insulin sensitivity. In conclusion, the addition of improved hepatic and peripheral insulin sensitivity to the list of beneficial metabolic effects of long-term DPP-IV inhibitor therapy provides strong support for the use of these compounds in the treatment of diabetes. 
In addition, Drucker et al. [19] found that GLP-1 regulates glucose homeostasis in the postprandial period by a number of mechanisms, including stimulation of insulin synthesis, inhibition of glucagon secretion, delay in gastric emptying, and promotion of satiety Sustained treatment with exogenous GLP-1 is suggested to impact beta cell regulation which is mostly compatible with the current study, which acts by inhibiting DPP-4 enzyme by sitagliptin so it increased the level of endogenous GLP-1 to affect beta cell proliferation. However, administration of exogenous GLP-1 is problematic as it is rapidly inactivated by the proteolytic enzyme DPP-4 within minutes of release. Therefore, it is better to use DPP-4 inhibitors which lead to inhibition of degradation of endogenous GLP-1 enhancing the incretin effect James et al. [24].

The present results demonstrated that monotherapy with sitagliptin and its combination with glimepiride increased the diameter of islets and keep it regular without vacuoles rather than in diabetic group. The proliferation marker, Ki-67 antigen, was used in our study to record the cell proliferation. Monotherapy with sitagliptin and its combination with glimepiride showed greater cell proliferation indicating the presence of actively dividing cells; this might explain the larger diameter of the pancreatic islets measured in H\&E stained sections.GLP-1 agonists have been reported to stimulate the growth and differentiation of pancreatic beta cell, as well as to exert cytoprotective and anti-apoptotic effects on beta-cell James et al. [24] . Thus, GLP-1 may be a means by which to create beta-cell ex vivo for transplantation into patients with insulinopenic type 1diabetes and severe forms of type 2 diabetes. In addition, long-term DPP-4 inhibitor therapy preserved and increased beta cell number through an apparent stimulation of islet neogenesis, beta cell regeneration (differentiation from precursor cells) as well as improved insulin biosynthesis in rat [23]

In this study, histological examination of the pancreas following DPP-4 inhibitor administration produced an increase in the diameter of pancreatic islets in type 2 diabetic rats. Preservation, neogenesis, or restoration of beta cell function is essential to alter or reverse the progression of the insulin secretory defect. Given the observations that GLP-1 stimulates proliferation of beta cell in rodents, and it may promote the differentiation of beta cell from human precursor cells. It seems reasonable to predict that DPP-4 inhibition, leading to increased levels of GLP-1, might also produce beneficial effects on beta cell diameter. Glucagon-like peptide-1 has been reported to reverse the loss of beta cell mass by both increasing new $\beta$-cell formation and decreasing $\beta$-cell apoptosis [25, 26]. The DPP-4 inhibitor (sitagliptin) increased GLP-1 concentrations [27] and modestly lowers glucose levels when used alone in type 2 diabetes Maedler et al. [28] with an additive effect in combination with other traditional antidiabetic drugs as shown through UK Prospective Diabetes Study (UKPDS) Group [29] such as sulphonylureas (glimepiride). In conclusion, this study provided evidence that daily treatment with sitagliptin in combination with glimepiride significantly enhanced glycemic control and preserved beta cell compared to monotherapies in type diabetic rats.

\section{CONCLUSIONS}

We can conclude that upon using a model of obese T2DM, the chronic treatment with inhibition of DPPIV by sitagliptin can correct the plasma glucose level and body weight loss and it's better to use its combination with glimepiride. This will have favorable effect on pancreatic islet proliferation which will produce a good glycemic control and will serve the pancreatic islet from loss by increase in its number so avoiding the great complications of diabetes.

\section{ACKBOWLEDGMENTS}

Authors wish to acknowledge Medical Union Pharmaceuticals (MUP, Ismailia, Egypt) for the generous gift of glimepiride.

\section{REFERENCE}

[1] DM. Nathan, JB. Buse, MB. Davidson, RJ.Heine, RR.Holman, R.Sherwin , B. Zinman. Management of hyperglycemia in type 2 diabetes: a consensus algorithm for the initiation and adjustment of therapy, Diabetes Care, 29, 2006, $1963-72$.

[2] SE. Inzucchi: Oral antihyperglycemic therapy for type 2 diabetes: scientific review, JAMA, 287, 2002, 360-372

[3] A. Bergman, D. Ebel, F. Liu, J. Stone, A. Wang, W. Zeng, L. Chen, S. Dilzer, K. Lasseter, G. Herman, J. Wagner, R. Krishna. Absolute bioavailability of Sitagliptin, an oral dipeptidyl peptidase-4 inhibitor, in healthy volunteers, Biopharm Drug Dispos, 28 , 2007, 315-322.

[4] DJ. Drucker, MA.Nauck. The incretin system: glucagon-like peptide-1 receptor agonists and dipeptidyl peptidase-4 inhibitors in type 2 diabetes, Lancet, 368, 2006, 1696-1705.

[5] R. Brazg, L. Xu, C. Dalla Man, C. Cobelli, K. Thomas, PP. Stein. Effect of adding sitagliptin, a dipeptidyl peptidase-4 inhibitor, to metformin on 24-h glycemic control and beta-cell function in patients with type 2 diabetes, Diabetes ObesMetab ,9, 2007, $186-193$.

[6] CF. Deacon, JJ. Holst. Dipeptidyl peptidase IV inhibition as an approach to the treatment and prevention of type 2 diabetes: a historical perspective. Biochem Biophys Res Commun, 294, 2002, 1-4.

[7] Sudre B, Broqua P, White RB, et al. Chronic inhibitionof circulating dipeptidyl peptidase IV by FE 999011 delays the occurrence of diabetes in male zucker diabetic fatty rats, Diabetes, 51, 2002, 1461-9.

[8] B. Ahren, JJ. Holst, H.Martensson, B. Balkan. Improvedglucose tolerance and insulin secretion by inhibition ofdipeptidyl peptidase IV in mice, Eur J Pharmacol, 239, 2000, 404-45. 
[9] RA. Pederson, HA. White, D. Schlenzig, RP. Pauly, CH. McIntosh, HU. Demuth. Improved glucose tolerance in Zucker fatty rats by oral administration of the dipeptidyl peptidase IV inhibitor isoleucine thiazolidide, Diabetes, 46, 1998, 1253-8.

[10] JA.Pospisilik, SG. Stafford, HU. Demuth, CH. McIntosh, RA Pederson. Long-term treatment with dipeptidyl peptidase IV inhibitor improves hepatic and peripheral insulin sensitivity in the VDF Zucker rat: a euglycemic-hyperinsulinemic clamp study, Diabetes, 51, 2002, 2677-83.

[11] Gadsby, Roger. Efficacy and Safety of Sitagliptin in the Treatment of Type 2 Diabetes, Clinical Medicine: Therapeutics, 1, 2009, 5362 .

[12] G. Herman, A. Bergman, F. Liu, C. Stevens, A. Wang, W. Zeng, L. Chen, K. Snyder, D. Hilliard, M. Tanen, W. Tanaka, A. Meehan, K. Lasseter, S. Dilzer, R. Blum, J. Wagner. Pharmacokinetics and Pharmacodynamic effects of the oral DPP-4 inhibitor sitagliptin in middle-aged obese subjects, J Clin Pharmacol, 46 (8), 2006, 876-86.

[13] GA. Herman, C. Stevens, K. Van Dyck, A. Bergman, B. Yi, M. De Smet, K. Snyder, D. Hilliard, M. Tanen, W. Tanaka, AQ. Wang, W. Zeng, D. Musson, G. Winchell, MJ. Davies, S. Ramael, KM. Gottesdiener, JA. Wagner. Pharmacokinetics and pharmacodynamics of sitagliptin, an inhibitor of dipeptidyl peptidase IV, in healthy subjects: results from two randomized, double-blind, placebocontrolled studies with single oral doses, Clin Pharmacol Ther., 78, 2005, 675-688.

[14] H. Hui, A. Nourparvar, X. Zhao, R. Perfetti R. Glucagon-like peptide-1 inhibits apoptosis of insulin-secreting cells via a cyclic 5'adenosine monophosphate-dependent protein kinase A- and a phosphatidylinositol 3-kinase-dependent path way , Endocrinology , 144, 2003, 1444-1455.

[15] D. Kim, L. Wang, M. Beconi, GJ. Eiermann, MH. Fisher, H. He, GJ. Hickey, JE. Kowalchick, B. Leiting, K. Lyons, F. Marsilio, ME. McCann, RA. Patel, A. Petrov, G. Scapin, SB. Patel, RS. Roy, JK. Wu, MJ. Wyvratt, BB. Zhang, L. Zhu, NA. Thornberry, AE. Weber. a potent, orally active dipeptidyl peptidase IV inhibitor for the treatment of type 2 diabetes, J Med Chem, 48, 2005,141-151.

[16] J. HuiJie Wang, X. Yuan Xiang Jin, S. Wan, N. Jing, W. Tao, J. Yong Jie Li, W. Zheng Wei Fu. Low dose streptozotocin (STZ) combined with high energy intake can effectively induce type 2 diabetes through altering the related gene expression, Asia Pac J Clin Nutr ,16 (Suppl 1), 2007, 412-417.

[17] A. Karasik, P. Aschner, H. Katzeff, MJ. Davies, PP. Stein. Sitagliptin, a DPP-4 inhibitor for the treatment of patients with type 2 diabetes: a review of recent clinical trials, Curr Med Res Opin., 24, 2008,489-96

[18] B. Ahren, R. Gomis, E. Standl, D. Mills, A. Schweizer. Twelve and 52-week efficacy of the dipeptidyl peptidase IV LAF237 in metformin-treated patients with type 2 diabetes, Diabetes Care, 27, 2004, 2874-80.

[19] DJ. Drucker, MA. Nauck. The incretin system: glucagon-like peptide-1 receptor agonists and dipeptidyl peptidase-4 inhibitors in type 2 diabetes, Lancet, 368, 2006, 1696-705.

[20] R. Scott, M. Wu, M. Sanchez, P. Stein. Efficacy and tolerability of the dipeptidyl peptidase-4 inhibitor sitagliptin as monotherapy over 12 weeks in patients with type 2 diabetes, Int J Clin Pract, 61,2007,171 -180.

[21] C. Mary, L. Sum. Sitagliptin, a Novel Drug for the Treatment of Type 2 Diabetes, Cardiology 15, 2007, 264-271.

[22] G. Roger. Efficacy and Safety of Sitagliptin in the Treatment of Type 2 Diabetes, Clinical Medicine: Therapeutics, 1, $2009,53-62$.

[23] A. John Pospisilik, G.Sara Stafford, D. Hans-Ulrich, H.S Christopher McIntosh, A. Raymond Pederson. Long-Term Treatment With Dipeptidyl Peptidase IV Inhibitor Improves Hepatic and Peripheral Insulin Sensitivity in the VDF Zucker Rat A Euglycemic Hyperinsulinemic Clamp Study, Diabetes, 51, 2002, 2677-2683.

[24] L. James, F. Joel Habener. Glucagon-like peptide 1 agonists and the development and growth of pancreatic beta-cells, American journal of physiology, Endocrinology and metabolism, 286 (6), 2004, E875-81.

[25] SH. Vincent, JR. Reed, AJ. Bergman, CS. Elmore, B. Zhu, S.Xu, D.Ebel, P. Larson, W. Zeng, L. Chen, S. Dilzer, K. Lasseter, K. Gottes diener, JA. Wagner, GA. Herman. Metabolism and excretion of the dipeptidyl peptidase 4 inhibitor [14C] sitagliptin in humans, Drug MetabDispos, 35, 2007, 533-538.

[26] S. Wild, G. Roglic, A. Green. Global prevalence of diabetes 2004: estimates for the year 2000 and projections for 2030, Diabetes Care, 27, 2004, 1047-53.

[27] G. Xu, DA. Stoffers, JF. Habener, S. Bonner-Weir. Exendin-4 stimulates both beta-cell replication and neogenesis, resulting in increased beta-cell mass and improved glucose tolerance in diabetic rats. Diabetes, 48, 1999, 2270-2276.

[28] K. Maedler, RD. Carr, D. Bosco, RA. Zuellig, T. Berney, MY.Donath. Sulfonylurea induced beta-cell apoptosis in cultured human islets, J Clin Endocrinol Metab. , 90, 2005, 501-506.

[29] UK Prospective Diabetes Study (UKPDS) Group, Intensive blood- glucose control with sulphonylureas or insulin compared with conventional treatment and risk of complications in patients with type 2 diabetes (UKPDS 33), Lancet, 352(9131), 1998, 837-53. 